Review

\title{
Web GIS-Based Public Health Surveillance Systems: A Systematic Review
}

\author{
Hui Luan ${ }^{1, *}$ and Jane Law ${ }^{1,2}$
}

1 School of Planning, Faculty of Environment, University of Waterloo, 200 University Avenue West, Waterloo, ON N2L 3G1, Canada; E-Mail: j9law@uwaterloo.ca

2 School of Public Health and Health Systems, Faculty of Applied Health Sciences, University of Waterloo, 200 University Avenue West, Waterloo, ON N2L 3G1, Canada

* Author to whom correspondence should be addressed; E-Mail: h3luan@uwaterloo.ca; Tel.: +1-519-888-4567 (ext. 31547).

Received: 26 November 2013; in revised form: 14 January 2014 / Accepted: 20 March 2014 / Published: 1 April 2014

\begin{abstract}
Web Geographic Information System (Web GIS) has been extensively and successfully exploited in various arenas. However, to date, the application of this technology in public health surveillance has yet to be systematically explored in the Web 2.0 era. We reviewed existing Web GIS-based Public Health Surveillance Systems (WGPHSSs) and assessed them based on 20 indicators adapted from previous studies. The indicators comprehensively cover various aspects of WGPHSS development, including metadata, data, cartography, data analysis, and technical aspects. Our literature search identified 58 relevant journal articles and 27 eligible WGPHSSs. Analyses of results revealed that WGPHSSs were frequently used for infectious-disease surveillance, and that geographical and performance inequalities existed in their development. The latest Web and Web GIS technologies have been used in developing WGPHSSs; however, significant deficiencies in data analysis, system compatibility, maintenance, and accessibility exist. A balance between public health surveillance and privacy concerns has yet to be struck. Use of news and social media as well as Web-user searching records as data sources, participatory public health surveillance, collaborations among health sectors at different spatial levels and among various disciplines, adaption or reuse of existing WGPHSSs, and adoption of geomashup and open-source development models were identified as the directions for advancing WGPHSSs.
\end{abstract}


Keywords: Web GIS; public health surveillance; spatial analysis; geomashup; open source; data access

\section{Introduction}

The last decade, especially the past five years, has witnessed the rapid growth of using Web Geographic Information System (Web GIS) in public health surveillance (PHS). As of late 2006, very few websites were devoted solely to health mapping [1]; however today, many countries and regions have realized the potential benefits of Web GIS for PHS and have developed their own Web GIS-based Public Health Surveillance Systems (WGPHSSs). Despite the rapid uptake, however, significant inequalities exist in the development and performance of WGPHSSs among countries.

While the applications of desktop GIS in public health have been extensively examined [2-6], an up-to-date systematic review of existing WGPHSSs is lacking. Early in 2003, Croner [7] comprehensively outlined the possibilities and challenges of using Web GIS in public health; nevertheless, Web GIS has dramatically evolved in the past ten years, especially with the incorporation of Web 2.0 into its development. Recent studies [1,8] have reviewed websites of contemporary Web GIS; however, these websites were not entirely dedicated to public health, let alone PHS. Moreover, the impact of Web 2.0 on Web GIS or PHS was not examined in these studies. The purpose of this paper is twofold: (1) to explore the status quo of WGPHSS development in different countries; and (2) to provide insights to WGPHSS designers and developers as well as public health professionals for the new implementations of WGPHSSs.

GIS has been widely adopted in public health as health data is inextricably linked to a specific location in the form of street addresses, postal codes, or latitudes and longitudes. Unlike other information systems used in PHS, GIS can improve the spatio-temporal aspect of PHS by supporting maps and spatial analysis. Specifically, maps can visually present geo-referenced health data in a straightforward manner, thereby easily communicating information to end users. Compared with raw numbers and graphs, maps can be better interpreted [5,9]. Although Nykiforuk and Flaman [4] categorized one of the GIS applications in public health as "disease surveillance", other health phenomena (e.g., injuries, birth defects, disabilities, oral health, etc.) have also been monitored with GIS.

With the development of the World Wide Web (WWW), GIS data and functionalities have become increasingly available online, resulting in the emergence of Web GIS. In comparison to desktop GIS, Web GIS supplies a more efficient platform for timely (sometimes real-time) integration and dissemination of geo-referenced health surveillance data, thereby enabling efficient data use and effective public health interventions [10]. Empowering end users at all levels to simultaneously view the same up-to-date health data [11] is another benefit of Web GIS. In addition, Web GIS can potentially reduce the costs of integrating GIS into public health practice by decreasing the amount of training required to use GIS and providing online training tutorials [8]. The transition from read-only Web 1.0 to read-write Web 2.0 has brought new possibilities for both Web GIS and PHS. Generally, the core principles of Web 2.0 include enriching Web users' experience, using Web as "a platform for computing and software development", stimulating user participation, and supporting lightweight 
programming [12], which have been adopted in Web GIS development, making Web GIS applications more "interactive, customizable, social, and multimedia-intensive" [13].

The following review consists of four sections. Section 2 describes the methodology of this research, in terms of (1) searching for existing WGPHSSs on the Internet and related journal articles from bibliographic databases; and (2) development of indicators for analyzing the WGPHSSs identified. Section 3 reports the results of the search and analysis, and Section 4 discusses directions for the development of WGPHSS and limitations of this study. Section 5 concludes with the contributions of this review and provides further insights into current and future WGPHSS development.

\section{Methods}

\subsection{Search for Existing WGPHSSs and Journal Articles}

To comprehensively search the literature for this inter-disciplinary topic, we used two bibliographic databases, Geobase and PubMed. The former focuses on geography, while the latter focuses on medicine. We also used Web of Science as it includes the Scientific Citation Index (SCI) and Social Science Citation Index (SSCI) publications - the main resources for analyzing scientific outputs, and covers articles about information technologies such as Web GIS.

The following expression was used to locate publications that contained search terms (in italics) in their subjects, abstracts, titles or keywords, and were published in English between 1 January 2000 and 31 March 2013. Specifically, “*” was used to retrieve variations on a word stem to broaden our search.

(web OR online OR internet) AND (gis OR "geographic * information system *") AND ("public health" OR disease) AND (surveillance OR monitor *)

We then screened the identified articles with a set of inclusion criteria. An eligible article should be available as full-text, discussing human rather than animal or plant or other related subjects, and relevant to at least one of the essential aspects of WGPHSSs - health data collection, analysis, presentation and interpretation. Notably, we included articles about monitoring diseases (e.g., West Nile Virus (WNV)) infecting not only humans but also birds and animals. We also examined eligible articles' reference lists for additional relevant articles not located during the search. Furthermore, with Google, we searched websites of health authorities (e.g., the World Health Organization (WHO) and the Centers for Disease Control and Prevention (CDC)) and different countries' public health agencies to identify WGPHSSs not documented in bibliographic databases.

Identified WGPHSSs were then further screened to exclude systems which did not continuously update their data, as data collection should be "ongoing" or "continuous" according to the definition of PHS [14]. Systems not entirely dedicated to public health were also excluded. Furthermore, we removed systems that were exclusive to professionals. The lack of public access to these WGPHSSs made it impossible to gather sufficient information to make valid conclusions. Finally, albeit documented in journal articles, inactive WGPHSSs were excluded. Again, the lack of information precluded definitive conclusions. 


\subsection{Indicators for Analyzing WGPHSSs}

To analyze the eligible WGPHSSs, we adapted 20 indicators from previous studies [1,8], omitting several, including "Speed of site startup", "Ease of use", "Map upload time", and "Query process time", that we deemed highly subjective as they depend upon the user's computer configurations and network speed. We also excluded the indicator "System accessibility" as we chose to explore exclusively those WGPHSSs that could be accessed by the public. However, we added three new indicators: "Thematic map type", "Geomashup", and "Open-source based". The former one is an important cartographic consideration in representing health phenomena, while the latter two examine whether a Web GIS is developed with easy and cost-effective models [15-17]. Specifically, as a hallmark of Web 2.0, a geomashup refers to "a Web page or application that dynamically combines contents or function from multiple Web sites", where "at least one of the contents or functions is georeferenced" [15]. These indicators were grouped into five categories-metadata, data, cartography, data analysis, and technical aspects (Table 1), and provided standardized criteria for comparing different WGPHSSs. In addition to the information documented in articles, we also garnered first-hand experience with the WGPHSSs' websites by personally accessing all of them.

Table 1. Indicators for analyzing Web GIS-based Public Health Surveillance Systems (WGPHSSs).

\begin{tabular}{|c|c|}
\hline Indicator & Description \\
\hline \multicolumn{2}{|l|}{ 1. Metadata } \\
\hline 1.1. Region & $\begin{array}{l}\text { The country that a WGPHSS is used for. If the system is for global use, this } \\
\text { indicator is not applicable. }\end{array}$ \\
\hline 1.2. Geographic scale & $\begin{array}{l}\text { The area level a WGPHSS is used at: local (L, e.g., county), regional } \\
\text { (R, e.g., state or province), national }(\mathrm{N}) \text {, or global }(\mathrm{G}) \text {. }\end{array}$ \\
\hline 13 Health phenomena & $\begin{array}{l}\text { The health phenomenon/phenomena being monitored in a WGPHSS, divided into } \\
\text { four categories in this paper: (i) infectious disease (e.g., flu, West Nile Virus, } \\
\text { dengue); (ii) chronic disease (e.g., cancer, diabetes); }\end{array}$ \\
\hline 1.3. Health phenomena & (iii) others (neither infectious nor chronic disease, e.g., injury, birth defects); and \\
\hline & (iv) comprehensive (more than one type of health phenomenon monitored in the \\
\hline & WGPHSS, e.g., both infectious and chronic diseases are monitored). \\
\hline 1.4. Data source & $\begin{array}{l}\text { Source }(\mathrm{s}) \text { of the health data in a WGPHSS. This indicator will be simplified to } \\
\text { either traditional }(\mathrm{Y}) \text { or non-traditional }(\mathrm{N}) \text {. }\end{array}$ \\
\hline 1.5. Data update cycle & $\begin{array}{l}\text { The cycle in which the health data is collected, also how often the health data is } \\
\text { updated in a WGPHSS: real-time, weekly, monthly, or annually. If the cycle } \\
\text { cannot be directly determined, we check the data currency instead. This indicator } \\
\text { can indirectly show how useful the WGPHSS is. }\end{array}$ \\
\hline 1.6. Data currency & The latest data a WGPHSS contains. \\
\hline \multicolumn{2}{|l|}{ 2. Data } \\
\hline 2.1. Printable map & $\begin{array}{l}\text { Whether map printing is supported in a WGPHSS (Y/N). Most Web browsers now } \\
\text { support directly printing web pages; however, this indicator refers specifically to } \\
\text { the ability to print only the map portion, usually via clicking a print-button. }\end{array}$ \\
\hline
\end{tabular}


Table 1. Cont.

\begin{tabular}{|c|c|}
\hline Indicator & Description \\
\hline \multicolumn{2}{|l|}{ 2. Data } \\
\hline 2.2. Tabular data & $\begin{array}{l}\text { Whether raw health data is provided in tables, and also whether data is } \\
\text { downloadable as Microsoft Excel, comma-separated values (CSV), or text files, or } \\
\text { files in other formats. There are three different cases: tabular data are not provided } \\
\text { in tables }(\mathrm{N}) \text {; tabular data are provided but not downloadable }(\mathrm{Y}) \text {; and tabular data } \\
\text { are provided and also downloadable }\left(\mathrm{Y}_{\mathrm{d}}\right) \text {. }\end{array}$ \\
\hline $\begin{array}{l}\text { 2.3. Socio-demographic/economic } \\
\text { or environmental data }\end{array}$ & $\begin{array}{l}\text { Whether socio-demographic/economic or environmental data is included in a } \\
\text { WGPHSS (Y/N). Comparing spatial patterns of health phenomena and that of } \\
\text { socio-demographic/economic and/or environmental data can help establish } \\
\text { hypotheses for further research. }\end{array}$ \\
\hline 2.4. Link to other sites & Whether they have links to other similar or relevant sites $(\mathrm{Y} / \mathrm{N})$. \\
\hline
\end{tabular}

\subsection{Color scheme}

3.2. Data classification

3.3. Time period

3.4. Map type

3.5. Thematic map type

3.6. Graph/Chart

\section{Data analysis}

4.1. Simple analysis

4.2. Advanced analysis

5. Technical aspects

5.1. Geomashup

5.2. Open-source based
Whether end users can change color scheme (Y/N).

Whether end users can change data classification methods $(\mathrm{Y} / \mathrm{N})$. Researchers agree that enabling users to change classification methods can help better explore the data [18].

Whether end users can specify the time span of a monitored health phenomenon $(\mathrm{Y} / \mathrm{N})$. If yes, historical data is also available for end users.

An indicator established based on how a map is presented over the Web: statically, interactively, or animatedly $[19,20]$. Static maps (S) are non-modifiable maps; interactive maps (I) are customized by inputting/changing parameters; and animated maps (A) can show a health phenomenon during a given time period or at different locations, or visualize different health indicators for highlighting changes.

Different from the indicator above, this indicator was established from the cartographic perspective. Map types include choropleth maps, isopleth maps, graduated symbol maps, dot maps, and cartograms, which are commonly used in thematic mapping. This indicator will be simplified as using choropleth map only $(\mathrm{Y})$ or not $(\mathrm{N})$, as to our knowledge, choropleth maps are most commonly used in representing health phenomena. If other thematic map types are used in the WGPHSS, information will be summarized in the results section.

Whether graphs/charts, such as lines, bars, and pies, are used in a WGPHSS (Y/N).

Whether a WGPHSS supports simple analysis, such as overlay, buffering, point-in-polygon, and descriptive statistics (Y/N).

Whether a WGPHSS supports advanced analysis, such as cluster detection (Y/N).

Whether a WGPHSS was developed in the form of a geomashup (Y/N). Whether a WGPHSS was developed with open-source software or platform (Y/N). 


\section{Results}

\subsection{Results of Search}

The bibliographic database search returned 21, 57 and 45 articles from Geobase, PubMed, and Web of Science, respectively. After removing duplicates and applying screening criteria, we identified 39 papers. Nineteen additional articles were found from these papers' reference lists. From the 58 articles and Google search, we identified 45 systems: twenty-seven WGPHSSs (Table 2) satisfied the criteria, while the remaining 18 (Table A1) did not. Notably, a portion of the 45 systems consists of health atlases, among which some (e.g., U.S. Cancer Statistics: An Interactive Atlas) update the data continuously while others (e.g., Pennsylvania Cancer Atlas) do not. Thus, we included the former ones only.

Table 2. List of eligible WGPHSSs for analysis.

\begin{tabular}{|c|c|c|}
\hline ID & Name & Website \\
\hline 1 & AEGIS Flu & http://aegis.chip.org/flu [21] \\
\hline 2 & BioCaster & http://born.nii.ac.jp [22] \\
\hline 3 & $\begin{array}{l}\text { CDC: Behavioral Risk Factor Surveillance } \\
\text { System }\end{array}$ & http://www.cdc.gov/brfss [23] \\
\hline 4 & CDC: Diabetes Public Health Resource & http://www.cdc.gov/diabetes [24] \\
\hline 5 & $\begin{array}{l}\text { CDC: Division for Heart Disease and } \\
\text { Stroke Prevention }\end{array}$ & http://www.cdc.gov/dhdsp [25] \\
\hline 6 & CDC: Division of Oral Health & http://www.cdc.gov/OralHealth [26] \\
\hline 7 & $\begin{array}{l}\text { CDC: U.S. Cancer Statistics: } \\
\text { An Interactive Atlas }\end{array}$ & http://apps.nccd.cdc.gov/DCPC_INCA [27] \\
\hline 8 & CDC: WISQARS ${ }^{\mathrm{TM}}$ & http://www.cdc.gov/injury/wisqars [28] \\
\hline 9 & CDC: WNV Activity \& Surveillance & http://www.cdc.gov/westnile [29] \\
\hline 10 & $\begin{array}{l}\text { Community Health Information System: } \\
\text { Breast Health Portal }\end{array}$ & $\begin{array}{l}\text { http://interactive-mapping.slehc.org/breast-health- } \\
\text { portal/census.aspx [30] }\end{array}$ \\
\hline 11 & $\begin{array}{l}\text { Community Health Information System: } \\
\text { Project Safety Net }\end{array}$ & $\begin{array}{l}\text { http://interactive-mapping.slehc.org/project-safety- } \\
\text { net/zip.aspx [31] }\end{array}$ \\
\hline 12 & EpiScanGIS & http://www.episcangis.org [32] \\
\hline 13 & EpiSPIDER & http://www.epispider.org [33] \\
\hline 14 & FloridaCHARTS & http://www.floridacharts.com [34] \\
\hline 15 & FluBreaks & http://dritte.org/flubreaks [35] \\
\hline 16 & Google Dengue Trends & http://www.google.org/denguetrends [36] \\
\hline 17 & Google Flu Trends & http://www.google.org/flutrends [37] \\
\hline 18 & HealthMap & http://www.healthmap.org [38] \\
\hline 19 & Kentucky Cancer Registry & http://www.cancer-rates.info/ky [39] \\
\hline 20 & Malaria Atlas Project & http://www.map.ox.ac.uk [40] \\
\hline 21 & $\begin{array}{l}\text { Pennsylvania's West Nile Virus } \\
\text { Surveillance Program }\end{array}$ & http://www.westnile.state.pa.us [41] \\
\hline 22 & $\begin{array}{l}\text { Public Health Agency of Canada: West } \\
\text { Nile Virus MONITOR }\end{array}$ & http://www.westnilevirus.gc.ca [42] \\
\hline 23 & Sentinelles & http://www.sentiweb.org [43] \\
\hline 24 & Smittskyddsinstitutet & http://www.smittskyddsinstitutet.se [44] \\
\hline 25 & WHO: DengueNet & http://www.who.int/denguenet [45] \\
\hline 26 & WHO: FluNet & http://www.who.int/influenza/gisrs_laboratory/flunet [46] \\
\hline 27 & WHO: Global Health Atlas & http://apps.who.int/globalatlas [47] \\
\hline
\end{tabular}


Table 3. Results of analysis of the 27 eligible WGPHSSs.

\begin{tabular}{|c|c|c|c|c|c|c|c|c|c|c|c|c|c|c|c|c|c|c|c|c|}
\hline \multirow[b]{2}{*}{ ID } & \multicolumn{6}{|c|}{ Metadata } & \multicolumn{4}{|c|}{ Data } & \multicolumn{6}{|c|}{ Cartography } & \multicolumn{2}{|c|}{ Data Analysis } & \multicolumn{2}{|c|}{ Technical Aspects } \\
\hline & 1.1 & 1.2 & 1.3 & 1.4 & 1.5 & 1.6 & 2.1 & 2.2 & 2.3 & 2.4 & 3.1 & 3.2 & 3.3 & 3.4 & 3.5 & 3.6 & 4.1 & 4.2 & 5.1 & 5.2 \\
\hline 1 & U.S. & $\mathrm{R}, \mathrm{L}$ & (i) & $\mathrm{Y}$ & Weekly & $2012-10-29$ & $\mathrm{~N}$ & $\mathrm{~N}$ & $\mathrm{~N}$ & $\mathrm{~N}$ & $\mathrm{~N}$ & $\mathrm{~N}$ & Y & I & Graduated symbol & $\mathrm{Y}$ & Y & $\mathrm{Y}$ & $\mathrm{Y}$ & Unknown \\
\hline 2 & $\mathrm{~N} / \mathrm{A}$ & $\mathrm{G}, \mathrm{N}$ & (i) & $\mathrm{N}$ & $30 \mathrm{mins}$ & 2014-01-04 & $\mathrm{N}$ & $\mathrm{Y}_{\mathrm{d}}$ & $\mathrm{N}$ & $\mathrm{N}$ & $\mathrm{N}$ & $\mathrm{N}$ & Y & $\mathrm{I}, \mathrm{A}$ & Color-coded symbol & $\mathrm{Y}$ & $\mathrm{Y}$ & $\mathrm{N}$ & $\mathrm{Y}$ & Unknown \\
\hline 3 & U.S. & $\mathrm{N}, \mathrm{R}, \mathrm{L}$ & (iv) & $\mathrm{Y}$ & Annually & 2011 & $\mathrm{Y}$ & $Y_{d}$ & $\mathrm{~N}$ & $\mathrm{Y}$ & $\mathrm{N}$ & Y & Y & I & Choropleth & Y & Y & $\mathrm{Y}$ & $\mathrm{N}$ & Unknown \\
\hline 4 & U.S. & $\mathrm{N}, \mathrm{R}, \mathrm{L}$ & (ii) & $\mathrm{Y}$ & Annually & 2010 & $\mathrm{Y}$ & $\mathrm{Y}_{\mathrm{d}}$ & $\mathrm{N}$ & $\mathrm{Y}$ & $\mathrm{N}$ & Y & Y & I, A & Choropleth & $\mathrm{Y}$ & $\mathrm{Y}$ & $\mathrm{N}$ & $\mathrm{N}$ & Unknown \\
\hline 5 & U.S. & $\mathrm{N}, \mathrm{R}, \mathrm{L}$ & (ii) & $\mathrm{Y}$ & Annually & 2010 & $\mathrm{Y}$ & $\mathrm{Y}$ & $\mathrm{Y}$ & $\mathrm{Y}$ & $\mathrm{N}$ & $\mathrm{N}$ & $\mathrm{Y}$ & $\mathrm{I}, \mathrm{A}$ & Choropleth & $\mathrm{Y}$ & $\mathrm{Y}$ & $\mathrm{N}$ & $\mathrm{Y}$ & Unknown \\
\hline 6 & U.S. & $\mathrm{N}, \mathrm{R}, \mathrm{L}$ & (iii) & $\mathrm{Y}$ & Biennially & 2008 & $\mathrm{Y}$ & $\mathrm{Y}$ & $\mathrm{Y}$ & $\mathrm{Y}$ & $\mathrm{N}$ & $\mathrm{N}$ & $\mathrm{Y}$ & I & Choropleth & $\mathrm{N}$ & $\mathrm{Y}$ & $\mathrm{N}$ & $\mathrm{N}$ & Unknown \\
\hline 7 & U.S. & $\mathrm{N}, \mathrm{R}$ & (ii) & $\mathrm{Y}$ & Annually & 2010 & $\mathrm{Y}$ & $\mathrm{Y}_{\mathrm{d}}$ & $\mathrm{N}$ & $\mathrm{N}$ & $\mathrm{N}$ & Y & $\mathrm{Y}$ & $\mathrm{I}, \mathrm{A}$ & Choropleth & $\mathrm{Y}$ & $\mathrm{Y}$ & $\mathrm{N}$ & $\mathrm{N}$ & Unknown \\
\hline 8 & U.S. & $\mathrm{N}, \mathrm{R}$ & (iii) & $\mathrm{Y}$ & Annually & Various & $\mathrm{Y}$ & $\mathrm{Y}_{\mathrm{d}}$ & $\mathrm{N}$ & $\mathrm{Y}$ & Y & Y & $\mathrm{Y}$ & I & Choropleth & $\mathrm{N}$ & $\mathrm{Y}$ & $\mathrm{N}$ & $\mathrm{N}$ & Unknown \\
\hline 9 & U.S. & $\mathrm{N}, \mathrm{R}, \mathrm{L}$ & (i) & $\mathrm{Y}$ & Weekly & $2013-12-03$ & $\mathrm{Y}$ & $\mathrm{Y}$ & $\mathrm{N}$ & $\mathrm{Y}$ & N/A & $\mathrm{N} / \mathrm{A}$ & N/A & S & Choropleth & $\mathrm{N}$ & Y & $\mathrm{N}$ & $\mathrm{N}$ & Unknown \\
\hline 10 & U.S. & $\mathrm{R}, \mathrm{L}$ & (ii) & $\mathrm{Y}$ & Annually & 2010 & $\mathrm{~N}$ & $\mathrm{~N}$ & $\mathrm{Y}$ & $\mathrm{N}$ & $\mathrm{N}$ & $\mathrm{N}$ & Y & I & Choropleth & $\mathrm{N}$ & Y & $\mathrm{N}$ & $\mathrm{Y}$ & Unknown \\
\hline 11 & U.S. & $\mathrm{R}, \mathrm{L}$ & (iv) & $\mathrm{Y}$ & Annually & 2008 & $\mathrm{~N}$ & $\mathrm{~N}$ & $\mathrm{Y}$ & $\mathrm{N}$ & $\mathrm{N}$ & $\mathrm{N}$ & Y & I & Choropleth & $\mathrm{N}$ & $\mathrm{Y}$ & $\mathrm{N}$ & $\mathrm{Y}$ & Unknown \\
\hline 12 & Germany & $\mathrm{N}, \mathrm{R}$ & (i) & $\mathrm{Y}$ & Weekly & 2014-01-03 & $\mathrm{Y}$ & $\mathrm{N}$ & $\mathrm{Y}$ & $\mathrm{N}$ & $\mathrm{N}$ & $\mathrm{N}$ & Y & I & Choropleth, symbol & $\mathrm{N}$ & $\mathrm{Y}$ & $\mathrm{Y}$ & $\mathrm{N}$ & Y \\
\hline 13 & $\mathrm{~N} / \mathrm{A}$ & $\mathrm{G}, \mathrm{N}$ & (i) & $\mathrm{N}$ & Real-time & 2014-01-04 & $\mathrm{N}$ & $\mathrm{N}$ & $\mathrm{N}$ & $\mathrm{Y}$ & $\mathrm{N}$ & $\mathrm{N}$ & Y & I & Graduated symbol & $\mathrm{Y}$ & $\mathrm{Y}$ & $\mathrm{N}$ & $\mathrm{Y}$ & Unknown \\
\hline 14 & U.S. & $\mathrm{R}, \mathrm{L}$ & (iv) & $\mathrm{Y}$ & Annually & Various & $\mathrm{Y}$ & $\mathrm{Y}_{\mathrm{d}}$ & $\mathrm{Y}$ & $\mathrm{Y}$ & $\mathrm{N}$ & $\mathrm{N}$ & $\mathrm{Y}$ & I & Choropleth & $\mathrm{Y}$ & $\mathrm{Y}$ & $\mathrm{N}$ & $\mathrm{Y}$ & Unknown \\
\hline 15 & U.S. & $\mathrm{N}, \mathrm{R}, \mathrm{L}$ & (i) & $\mathrm{N}$ & Weekly & 2014-01-03 & $\mathrm{N}$ & $\mathrm{N}$ & $\mathrm{N}$ & $\mathrm{N}$ & $\mathrm{N}$ & $\mathrm{N}$ & $\mathrm{N}$ & I & Choropleth & $\mathrm{Y}$ & $\mathrm{Y}$ & $\mathrm{Y}$ & $\mathrm{Y}$ & Unknown \\
\hline 16 & $\mathrm{~N} / \mathrm{A}$ & $\mathrm{G}, \mathrm{N}, \mathrm{R}$ & (i) & $\mathrm{N}$ & Weekly & 2014-01-03 & $\mathrm{N}$ & $\mathrm{Y}_{\mathrm{d}}$ & $\mathrm{N}$ & $\mathrm{Y}$ & $\mathrm{N}$ & $\mathrm{N}$ & $\mathrm{N}$ & I & Choropleth & $\mathrm{Y}$ & $\mathrm{N}$ & $\mathrm{N}$ & $\mathrm{Y}$ & Unknown \\
\hline 17 & N/A & $\mathrm{G}, \mathrm{N}, \mathrm{R}$ & (i) & $\mathrm{N}$ & Weekly & 2014-01-03 & $\mathrm{N}$ & $\mathrm{Y}_{\mathrm{d}}$ & $\mathrm{N}$ & $\mathrm{Y}$ & $\mathrm{N}$ & $\mathrm{N}$ & $\mathrm{N}$ & I & Choropleth & $\mathrm{Y}$ & $\mathrm{Y}$ & $\mathrm{N}$ & $\mathrm{Y}$ & Unknown \\
\hline 18 & N/A & $\mathrm{G}, \mathrm{N}, \mathrm{R}, \mathrm{L}$ & (i) & $\mathrm{N}$ & Hourly & 2014-01-04 & $\mathrm{N}$ & $\mathrm{N}$ & $\mathrm{N}$ & $\mathrm{Y}$ & $\mathrm{N}$ & $\mathrm{N}$ & $\mathrm{Y}$ & I & Graduated symbol & $\mathrm{N}$ & $\mathrm{Y}$ & $\mathrm{N}$ & $\mathrm{Y}$ & Unknown \\
\hline 19 & U.S. & $\mathrm{R}, \mathrm{L}$ & (ii) & $\mathrm{Y}$ & Annually & 2011 & $\mathrm{Y}$ & $\mathrm{Y}_{\mathrm{d}}$ & $\mathrm{Y}$ & $\mathrm{Y}$ & $\mathrm{N}$ & $\mathrm{N}$ & Y & I & Choropleth & Y & Y & $\mathrm{N}$ & $\mathrm{N}$ & Unknown \\
\hline 20 & $\mathrm{~N} / \mathrm{A}$ & $\mathrm{G}, \mathrm{N}$ & (i) & $\mathrm{Y}$ & Annually & 2010 & $\mathrm{~N}$ & $\mathrm{Y}_{\mathrm{d}}$ & $\mathrm{N}$ & $\mathrm{Y}$ & $\mathrm{N}$ & $\mathrm{N}$ & $\mathrm{N}$ & $\mathrm{S}, \mathrm{I}$ & Choropleth, color-coded symbol, dot & $\mathrm{N}$ & Y & $\mathrm{Y}$ & $\mathrm{Y}$ & Y \\
\hline 21 & U.S. & $\mathrm{R}, \mathrm{L}$ & (i) & $\mathrm{Y}$ & Weekly & 2013-09 & $\mathrm{N}$ & Y & $\mathrm{N}$ & $\mathrm{Y}$ & N/A & N/A & N/A & S & Choropleth & $\mathrm{Y}$ & $\mathrm{Y}$ & $\mathrm{N}$ & $\mathrm{N}$ & Unknown \\
\hline 22 & Canada & $\mathrm{N}, \mathrm{R}$ & (i) & $\mathrm{Y}$ & Weekly & 2013-11-09 & $\mathrm{N}$ & $\mathrm{Y}_{\mathrm{d}}$ & $\mathrm{N}$ & $\mathrm{Y}$ & N/A & N/A & N/A & S & Choropleth & $\mathrm{N}$ & $\mathrm{Y}$ & $\mathrm{N}$ & $\mathrm{N}$ & Unknown \\
\hline 23 & France & $\mathrm{N}, \mathrm{R}$ & (i) & $\mathrm{Y}$ & Weekly & $2013-12-29$ & $\mathrm{~N}$ & $\mathrm{Y}_{\mathrm{d}}$ & $\mathrm{N}$ & $\mathrm{Y}$ & $\mathrm{N}$ & $\mathrm{N}$ & Y & $\mathrm{S}, \mathrm{I}, \mathrm{A}$ & Isopleth & $\mathrm{Y}$ & $\mathrm{Y}$ & $\mathrm{N}$ & $\mathrm{N}$ & Unknown \\
\hline 24 & Sweden & $\mathrm{N}, \mathrm{R}$ & (i) & $\mathrm{Y}$ & Monthly & 2013-12 & $\mathrm{N}$ & $\mathrm{Y}_{\mathrm{d}}$ & $\mathrm{N}$ & $\mathrm{Y}$ & N/A & N/A & N/A & S & Choropleth & $\mathrm{Y}$ & Y & $\mathrm{N}$ & $\mathrm{N}$ & Unknown \\
\hline 25 & N/A & $\mathrm{G}, \mathrm{N}, \mathrm{R}$ & (i) & $\mathrm{Y}$ & Monthly & 2011 & $\mathrm{~N}$ & $\mathrm{Y}_{\mathrm{d}}$ & $\mathrm{N}$ & $\mathrm{Y}$ & $\mathrm{N}$ & $\mathrm{N}$ & Y & $\mathrm{S}, \mathrm{I}$ & Choropleth, symbol & Y & Y & $\mathrm{N}$ & $\mathrm{N}$ & Unknown \\
\hline 26 & N/A & $\mathrm{G}, \mathrm{N}, \mathrm{R}$ & (i) & $\mathrm{Y}$ & Weekly & 2014-01 & $\mathrm{N}$ & $\mathrm{Y}_{\mathrm{d}}$ & $\mathrm{N}$ & $\mathrm{Y}$ & $\mathrm{N}$ & $\mathrm{N}$ & $\mathrm{Y}$ & $\mathrm{S}, \mathrm{I}$ & Choropleth, symbol & $\mathrm{Y}$ & $\mathrm{Y}$ & $\mathrm{N}$ & $\mathrm{N}$ & Unknown \\
\hline 27 & $\mathrm{~N} / \mathrm{A}$ & $\mathrm{G}, \mathrm{N}, \mathrm{R}$ & (iv) & $\mathrm{Y}$ & Various & Various & $\mathrm{N}$ & $\mathrm{Y}_{\mathrm{d}}$ & $\mathrm{N}$ & $\mathrm{Y}$ & $\mathrm{N}$ & $\mathrm{N}$ & $\mathrm{Y}$ & $\mathrm{S}, \mathrm{I}$ & Choropleth, symbol & $\mathrm{Y}$ & $\mathrm{Y}$ & $\mathrm{N}$ & $\mathrm{N}$ & Unknown \\
\hline
\end{tabular}

Note: (1) All websites were investigated before and revisited on 4 January 2014; (2) N/A means the indicator was not applicable; (3) "Unknown" means the indicator could not be determined based on available information; (4) Refer to Table 1 for descriptions of the 20 indicators. 


\subsection{Analysis of Results}

Table 3 presents the analysis results of the 27 WGPHSSs based on the 20 indicators. The results are briefly summarized below.

\subsubsection{Metadata}

Nine of the 27 WGPHSSs monitor health phenomena at the global level. Of the remaining 18 not for global surveillance, 14 are used by the U.S. and one each by Canada, France, Germany, and Sweden. Half of the U.S.'s WGPHSSs were developed by the CDC. In addition, several states of the U.S., namely, Florida, Kentucky, Massachusetts, Pennsylvania, and Texas, have developed their own WGPHSSs. Interestingly, all WGPHSSs monitor health phenomena on two or more geographical scales. HealthMap even monitors at all four spatial levels. Moreover, although FluBreaks uses the surveillance data from Google Flu Trends, its statistical analysis methods are currently only available for the U.S. at national, regional, and local levels.

Infectious diseases account for the greatest percentage (15 of 27) of monitored health phenomena, followed by chronic diseases (6), comprehensive (4), and others (2). Flu, WNV, and dengue are the top three infectious diseases monitored, while cancer is the most frequently monitored chronic disease. The majority (21 of 27) of WGPHSSs collect data from authorized public health agencies. In contrast, the remaining six use informal online information. Specifically, three report-based WGPHSSs, BioCaster, EpiSPIDER, and HealthMap, collect data from news and social media sites (e.g., RSS news, ProMED-mail, Twitter, etc.), while the other three, Google Flu Trends, Google Dengue Trends, and FluBreaks, use Google search data.

WGPHSSs for infectious diseases update their data on a monthly basis at the minimum, with the exception of the Malaria Atlas Project, which does so annually. At the other end of the spectrum, EpiSPIDER updates in real-time. Conversely, WGPHSSs for non-infectious health conditions are usually updated annually. As for data currency, data in infectious disease-oriented WGPHSSs is updated at least to September 2013, except for AEGIS Flu, Malaria Atlas Project, and DengueNet. This is unsurprising as infectious disease data is usually updated at short intervals. Data currency, however, varies to a much larger extent among non-infectious disease-oriented WGPHSSs, with the last updates ranging from 2006 to 2012. Furthermore, data currency varies among individual health indicators within comprehensive-oriented WGPHSSs, for example, in FloridaCHARTS. Of note, FloridaCHARTS is most comprehensive in terms of data resources and data currency. It covers a number of health indicators for Florida, with a range from commonly monitored infectious and chronic diseases to uncommonly monitored injuries and violence, among others. Even for uncommonly monitored health phenomena, FloridaCHARTS has the data updated to 2011 or 2012.

\subsubsection{Data}

Approximately one third of the WGPHSSs' maps are printable. Seven WGPHSSs do not provide tabular raw health data. Of the 20 that do, 16 support downloadable tabular data as Excel, CSV, or text files. A small number (seven of 27) provide related socio-demographic/economic/environmental data as well. CDC's Division for Heart Disease and Stroke Prevention has the most comprehensive dataset. 
In addition to heart disease and stroke data (e.g., mortality, hospitalization, and hospital discharge status), it also provides information on health determinants, including both social (e.g., poverty, unemployment rate, education, race/ethnicity, etc.) and physical (e.g., grocery stores, supermarkets, club stores, convenience stores, and fast food restaurants) environments. Lastly, over two thirds (20 of 27) of the WGPHSSs have links to other related websites.

\subsubsection{Cartography}

Four WGPHSSs do not support interactive mapping, therefore indicators 3.1-3.3 are applicable to 23 WGPHSSs only. Of these 23 WGPHSSs, only one (WISQARS ${ }^{T M}$ ) supports color scheme customization, four support data classification method customization, and 19 support time period customization. Atlas-oriented WGPHSSs (e.g., U.S. Cancer Statistics: An Interactive Atlas) usually support customization of classification methods or color schemes. Health indicator and map level are two other frequently customizable parameters. Relatively uncommon customizable parameters, including gender, age, race/ethnicity, number of map classes, and (spatial) smoothing, are also identified (Table 4). Supporting almost all the identified customizable parameters, WISQARS ${ }^{T M}$ exemplifies the most comprehensive WGPHSS in terms of map customization.

Table 4. WGPHSSs supporting customizing gender, age, race/ethnicity, classes, and (spatial) smoothing.

\begin{tabular}{cl}
\hline Parameter & \multicolumn{1}{c}{ WGPHSS } \\
\hline \multirow{2}{*}{ Gender } & Division for Heart Disease and Stroke Prevention; U.S. Cancer Statistics: An \\
& Interactive Atlas; WISQARS ${ }^{\mathrm{TM}}$; FloridaCHARTS; Kentucky Cancer Registry \\
Age & AEGIS Flu; Division for Heart Disease and Stroke Prevention; WISQARS ${ }^{\mathrm{TM}} ;$ \\
Race/Ethnicity & Division for Heart Disease and Stroke Prevention; U.S. Cancer Statistics: An $^{\text {Interactive Atlas; WISQARS }}{ }^{\mathrm{TM}}$; FloridaCHARTS; Kentucky Cancer Registry \\
& Behavioral Risk Factor Surveillance System; Diabetes Public Health Resource; \\
Classes & U.S. Cancer Statistics: An Interactive Atlas; WISQARS \\
& AEGIS Flu; Division for Heart Disease and Stroke Prevention; WISQARS \\
\hline
\end{tabular}

Not surprisingly, the majority of WGPHSSs support interactive mapping since the widespread distribution of maps over the Web is mainly attributed to the rapid growth of "Web-based interactive maps" [1,20]. In contrast, static maps and animated maps are only provided in nine and five WGPHSSs, respectively. Choropleth maps are the most utilized thematic maps (by 22 WGPHSSs); however, 17 of these 22 only use choropleth maps. Meanwhile, symbol maps (graduated or color-coded), dot maps, and isopleth maps are used by nine, one, and one WGPHSS(s), respectively. Graphs/Charts are provided by two-thirds of the WGPHSSs, but most lack sophistication and are just simple and traditional line, bar, or pie graphs/charts. In this respect, the Diabetes Interactive Atlases, part of the CDC's diabetes surveillance program, distinguishes itself by including less commonly used bubble and candlestick charts. 


\subsubsection{Data Analysis}

Almost all WGPHSSs, except for Google Dengue Trends, support simple analysis, with descriptive analysis and simple trend analysis being the most common methods. Generally, the trend of a health phenomenon can be analyzed by referring to the line or bar graphs. BioCaster stands out as the only one to recruit an external Web system-DIZIE - to perform the trend analysis. GIS overlay is also implemented in several WGPHSSs, such as EpiScanGIS and Division for Heart Disease and Stroke Prevention. Remarkably, multi-map comparison, a simple analytical method discussed by Rinner et al. [18], is supported in only three WGPHSSs: AEGIS Flu, Division for Heart Disease and Stroke Prevention, and U.S. Cancer Statistics: An Interactive Atlas. Conversely, advanced analyses are supported in only five WGPHSSs, each using different methods (Table 5). It is worth noting that EpiScanGIS and Malaria Atlas Projects adopt external analysis software rather than embedding analytical functions within their systems.

Table 5. Advanced analysis supported in corresponding WGPHSSs.

\begin{tabular}{cl}
\hline WGPHSS & \multicolumn{1}{c}{ Advanced Analysis Methods } \\
\hline AEGIS Flu & Cross-correlation \\
EpiScanGIS & Cluster analysis \\
CDC: Behavioral Risk Factor & (1) Cross tabulation \\
Surveillance System & (2) Logistic regression \\
FluBreaks & (1) Rapid response analysis, e.g., Poisson CUSUM \\
Malaria Atlas Project & (2) Historical analysis, e.g., Historical limits method \\
\hline
\end{tabular}

\subsubsection{Technical Aspects}

Twelve WGPHSSs are geomashups, and half use Google Maps as their base map. The health information layer in each geomashup is generated with the data from the WGPHSS itself or from aforementioned informal online information. Unsurprisingly, all WGPHSSs using informal data were developed in the form of geomashups since these informal data are some of the Web resources combined by these systems. Beyond the Google Maps Application Programming Interface (API), other web services and browser-side APIs were also utilized to access and process the base map and/or informal health information: uClassify, OpenCalais, and AlchemyAPI were used for building EpiSPIDER [33]; ArcGIS API for Flex was used for developing FloridaCHARTS and Interactive Atlas of Heart Disease and Stroke (part of CDC's heart disease and stroke surveillance system). In contrast, based on available information, only two WGPHSSs were developed with open-source platform or software: Malaria Atlas Project used OpenLayers, while EpiScanGIS employed OpenLaszlo, UMN Mapserver, PostgreSQL, and PostGIS [48].

\section{Discussion}

Based on the above analysis, we discuss below our observations and thoughts for developing a successful WGPHSS in terms of health data collection and update, data analysis, user interface design, 
use of maps and charts, system maintenance and compatibility, privacy issues of health data, development costs, and training. We then discuss the limitations of this review.

\subsection{Health Data Collection}

Data collection methods vary widely among the WGPHSSs. Although most systems still use official health data (e.g., EpiScanGIS uses the meningococcal case registry data from the National Reference Centre for Meningococci (NRZM) [49]), emerging technologies, especially Web 2.0, have profoundly revolutionized the way through which health data is collected.

First, data from news and social media, and Web-user search, have been extensively used for PHS. In addition to the six WGPHSSs analyzed in this paper, previous studies also demonstrated the widespread use of this informal online information. For example, Twitter has been used to monitor dental pain [50], H1N1 [51], cholera [52], and Enterohemorrhagic Escherichia coli (EHEC)/ hemolytic uremic syndrome (HUS) [53]; Web-user search data has been proven to have the possibility to effectively monitor H1N1 [54] and toxicological outbreaks [55]; and Google Flu Trends has been employed for flu surveillance in various countries worldwide [56-61]. Unlike official data, these informal data are much less costly to obtain, more timely (often 1-2 weeks earlier $[52,56,62]$ ) thus allowing for early outbreak detection and responses, more frequently posted, and are generated worldwide making large spatial scale PHS a reality [50]. Second, the crowdsourcing technology has enabled public participation in PHS, hence making it possible to collect information not included in traditional datasets [63]. The public can engage via smartphones (usually equipped with a built-in Global Positioning System (GPS) and apps for PHS [64]), online social network applications [65], or other mobile devices (e.g., tablets and netbooks). For example, end users of HealthMap can submit information on local outbreaks via the website or the app-HealthMap: Outbreaks Near Me-on mobile devices with Apple iOS or Android platform. More in-depth and detailed information about crowdsourcing technologies for PHS can be found in the review by Kamel Boulos et al. [66]. Data from this voluntary participation can be viewed as proactive, while conversely, data from news and social media, and Web-user search can be considered passive.

Nevertheless, problems exist in both approaches. First, certain biases are probably inevitable in informal data sources [52], including geographical biases (media are much more prevalent in developed regions), demographic biases (a certain gender or age group may contribute more data via the social media platform), and cultural biases (different meanings in different regions or languages [67] can result in misguided reporting and therefore lead to inaccurate or even false information). Thus, besides existing platforms such as SwiftRiver [68], more filtering and validating models are needed for informal data before it can be used effectively and accurately [66,69]. There are encouraging signs, however, that informal data can be used reliably, as preliminary experiments from DIZIE's development team have verified that respiratory data in the U.S. from Twitter correlates well with data from the CDC [70]. Second, challenges arise in extracting and integrating information from data in "different file formats, schemas, naming systems" [71] and languages, and are subjects being discussed in several studies [72,73]. Third, existing ethical issues are rarely explored in passive data collection (e.g., from Twitter). To use the application or service, consumers are likely to accept the agreement for sharing their personal information without fully understanding associated risks [63]. Despite these 
limitations and potential issues, informal data is a promising source for PHS and at minimum can be a highly useful complement to official data. As in the case of an outbreak, where even if social media cannot confirm an outbreak, it can "contribute to an investigation" [69]. Furthermore, for resource-constrained regions where official data is scarce, informal data may become a vital source of health information [74]. As such, future WGPHSS development will certainly continue to increasingly leverage these resources.

\subsection{Health Data Update}

An issue relevant to data collection methods is the updating of health data. Ideally, the health data in a WGPHSS should be as current as possible. However, for WGPHSSs monitoring non-communicable diseases or health conditions, this is not the usual case. Generally, factors, including the health phenomena being monitored, the level at which these phenomena were reported, and the availability of health data, affect how routinely WGPHSSs are updated [75]. The full impact of delayed updates to WGPHSSs is unknown, but worthwhile exploring. With the development of today's medical devices and public participation, continuously updating health data should be a feasible task [76]. As many WGPHSSs are still unable to update at timely and routine intervals, concerns have arisen as to whether administrative restrictions or/and technology restrictions, among others, are hindering data updating.

\subsection{Data Analysis}

Data analysis capabilities in existing WGPHSSs should be strengthened and extended as these analytical tools are vital in transforming raw data into knowledge. The ultimate goal of PHS is to inform the health planners and decision makers who are responsible for potential disease control, intervention, and prevention. This goal requires substantially more information than what raw health data provides. Without sound analyses, and in particular those supported by proper statistical models, to produce new and value-added information, WGPHSSs will remain "data rich" but "information poor" [77]. In fact, only by combining the use of mapping and data analysis techniques can spatial disease patterns be identified [78]; however, our findings suggest that most of the identified WGPHSSs focus solely on data sharing and visualization. To uncover more useful, value-added information, WGPHSSs should employ more spatial and non-spatial analysis methods, especially when they are used by decision makers. As an example, Bayesian spatial analysis can be incorporated to provide more reliable estimates of disease risks in small areas [79]. Some WGPHSSs use standalone data analysis software as a solution to address the lack of embedded analysis tools. For example, EpiScanGIS uses SaTScan to perform cluster analysis [49]. Although more evidence is needed, we believe embedding analysis functionalities in WGPHSSs can streamline the process of PHS. Given that the implementation is much more complicated in a Web context than in the desktop context, a possible solution would be for WGPHSSs to incorporate an existing suite of online analytical tools. For example, Google Flu Trends enables comparison of flu trends across regions with the online data analysis tool-Google Public Data Explorer. Breast Health Portal and Project Safety Net will similarly enable the use of Google Public Data Explorer in upcoming versions [80]. Likewise, Bernier et al. [81] have successfully combined GIS and Spatial On-Line Analytical Processing (SOLAP) - a technology devoted to spatio-temporal surveillance data analysis, employed primarily in Business Intelligence (BI) - for improved monitoring of climate-related health issues. An alternative 
variation is FluBreaks, a WGPHSS that uses Google Flu Trend data while providing its own sophisticated suite of statistical analysis tools. Future WGPHSS development should explore how to further leverage these combination modes.

\subsection{User Interface Design}

An effective WGPHSS relies on a good user interface. As stated by Frank [82], "the user interface is the system". WGPHSS users come from vastly different backgrounds, and most are not technical, cartographic, or statistical experts. A good WGPHSS should allow end users to expediently access and query data even if they are unfamiliar with GIS [83]. As such, potential end users are key stakeholders and their needs and opinions regarding user interface design are of paramount importance and must be solicited if a WGPHSS is to be successful. For instance, non-technical people were consulted to help design the user interface of the Multi-Agency Internet Geographic Information Service (MAIGIS) project [83]. Furthermore, we found that interactive mapping has become an indispensable functionality of a WGPHSS. However, improper map customization options risk misinforming end users, making appropriate customization-settings design a necessity. WGPHSS designers should follow sound cartographic and statistical principles when designing the default customization settings in an interactive Web context [84]. A good user-customized health map should enable not only easy interpretation, but also effective communication of health information, especially in instances where the raw data used to produce the maps is not tabulated. In a pilot study exploring public health practitioners' preferences and visual perceptions about geographic information, Koenig et al. [77] found that novice users of disease maps had difficulties comprehending data classifications and information expressed by charts (e.g., histograms and plot boxes) and understanding linkages between tabular data and disease maps. Moreover, novices frequently disagreed on what constituted appropriate color schemes. Therefore, WGPHSS designers should carefully configure these settings and determine whether end users will be allowed to change data classification methods (e.g., equal intervals, natural breaks, quantiles, optimal classifications, etc.) or color schemes (sequential or diverging color scheme), and the extent to which these elements can be changed.

\subsection{Use of Maps and Charts}

Current WGPHSSs can benefit from incorporating different types of maps and charts to represent health phenomena for analytical purposes. We found that animated maps are being underused in existing WGPHSSs compared with static and interactive maps. However, we believe animated maps should be much more widely adopted in PHS due to their ability to capture the inherent temporal feature of health phenomena. It has also been demonstrated that users can more accurately identify space-time clusters from animated maps than from multiple static maps [85]. Several factors facilitate the increased use of animated maps in WGPHSSs, namely, decreased costs, increased bandwidth, better streaming technology, smaller-sized format (vector rather than raster-based animation), automated creation procedures [86], and available animation technologies (e.g., Adobe Flash, Microsoft Silverlight). Some researchers asserted that animated maps could be further improved and even more useful if they provided more options, such as a pause functionality and pace manipulation [87]. However, rapidly improving technologies have since rectified these missing functionalities and 
rendered those concerns non-issues. For example, U.S. Cancer Statistics: An Interactive Atlas, Diabetes Interactive Atlases, and Interactive Atlas of Heart Disease and Stroke were developed using Adobe Flash to provide animated mapping capabilities and all of them support play/pause functionalities. Particularly, users of Interactive Atlas of Heart Disease and Stroke also can manipulate the pace of playing animated maps.

The majority of WGPHSSs use only choropleth maps; however, other types of thematic maps, such as graduated symbol maps, isopleth maps, and cartograms can provide an abundance of additional information. Unlike choropleth maps, graduated symbol maps use symbols in proportional sizes or graduated colors (e.g., in HealthMap) to better express a health phenomenon's severity. Isopleth maps have a much greater ability to reveal spatial patterns, as the health phenomena being mapped are not restricted to arbitrarily defined region boundaries. Moreover, isopleth maps represent health phenomena with a continuous surface, and therefore can provide local details that cannot be expressed with choropleth maps [88]. A final alternative, cartograms, can convey information on a specific health indicator by distorting geometry or space proportionally. This helps highlight trends to the user, especially extreme values. Examples of using graduated maps, isopleth maps, and cartograms to represent health phenomena can be found on the websites [89-91]. Similarly, beyond the traditional line, bar, or pie charts, unconventional chart types, including cartographic charts (e.g., pyramid charts, which have been used in the Pennsylvania Cancer Atlas [92]) and charts commonly used in other domains (e.g., candlestick and bubble charts), need to be implemented more frequently in WGPHSSs for better health information communication. Despite the usefulness of these additional maps and charts, an interpretation problem (especially for those not so commonly used, e.g., cartograms) may arise for end users without a cartography background. Thus, further research is needed to examine balancing cartographic map/chart use and interpretation improvement.

\subsection{System Maintenance and Compatibility}

System maintenance and compatibility of WGPHSSs are important elements that still pose significant challenges. Not all WGPHSSs documented in the articles could be explored online because some systems' Uniform Resource Locators (URLs) were invalid or could not be found. Interestingly, Disease Surveillance On-Line-the WGSPHSS developed by the Public Health Agency of Canada, for modifiable diseases, cancer, and injury surveillance-could be located in July 2013, but not on 6 August 2013 (the day we revisited all WGPHSSs' websites for the first time). This may indicate that system maintenance is an issue. Lack of further financial and human investment might be a barrier to the ongoing maintenance, as some WGPHSSs may no longer be employed after a health emergency is over. Theoretically, any WGPHSS can be modified or extended to monitor other health phenomena, so maintaining these systems at a minimum cost for future use would be invaluable. From time to time, systems may have their URLs changed. Hence, it should be ensured that redirecting users from the old websites to the new ones is supported.

Meanwhile, some systems must be operated with a specific Web browser (e.g., AEGIS Flu is currently supported only in Mozilla Firefox; Breast Health Portal, Project Safety Net, and EpiSPIDER do not work optimally in Internet Explorer), leading to browser incompatibility issues. Different end users prefer using different Web browsers (e.g., Internet Explorer, Google Chrome, Opera, Apple Safari, 
Mozilla Firefox, etc.), or their options may be dictated by the different operating systems they are using (e.g., Windows, Mac, Linux, etc.). Therefore, browser incompatibility is highly problematic for end users, as they may be unable to properly view the systems. Realistically however, enabling WGPHHSs to be compatible with all Web browsers requires additional development efforts, which may be unfeasible. One compromise is to develop WGPHSSs to fit a Web browser such as Google Chrome that can be used on multiple operating systems. Using Rich Internet Application (RIA, usually refers to "Web applications that provide a rich and engaging user experience comparable to desktop applications" [93]) technologies such as Adobe Flash/Flex, Microsoft Silverlight, and JavaFX to develop WGPHSSs is another solution for Web-browser and operating-system incompatibility issues. Uniquely, RIA requires installation of browser plug-ins before launching the application, which remains a debatable issue among Web application developers. Nevertheless, since almost all Web browsers support installing plug-ins, RIA-based WGPHSSs can be operated across different browsers. For example, WGPHSSs developed with Adobe Flash (e.g., EpiScanGIS) can be operated in any Web browser on any operating system that supports Adobe Flash Player. However, loading RIA-based WGPHSSs demands higher network bandwidth than non-RIA ones, an issue requiring special attention in WGPHSS development.

\subsection{Privacy Issues of Health Data}

Health data privacy concerns remain prominent barriers to efficient data analyses and system accessibility. Previous research has demonstrated the possibility of re-identifying patients' location information from low-resolution maps [94]. Therefore, geo-referenced health data is always aggregately released at a small map scale (e.g., provincial, regional, county, or health unit level) over the Web, severely limiting their ability to outline local trends, and identify precise locations of areas of interest (e.g., disease clusters) and their corresponding characteristics (associated with the clusters). These privacy issues also lead to restricted WGPHSS access, thereby limiting the use of these systems in health planning. For example, AEGIS is accessible only by public health professionals. These exclusive WGPHSSs are more comprehensive in terms of health data and analysis functionalities; and as such, the information they provide would be invaluable for evidence-based health planning. With the implications of the built environment on public health being heavily considered in planning processes, urban planners must be able to access the detailed health information contained in these WGPHSSs so they can make evidence-informed decisions. Thus, measures and policies allowing this access while safeguarding confidentiality and security need to be developed as soon as possible. The literature suggests that harmonizing privacy legislation with public health research demands, developing and providing toolsets, algorithms and guidelines for utilizing disaggregate health data, educating the community, and simplifying bureaucracies [95] are potential approaches to balancing the protection of health data privacy and the provision of detailed health information.

\subsection{Development Costs}

The resource requirements for development and training are perhaps the greatest challenges in the global acceptance and use of WGPHSSs. Developing a WGPHSS can in fact be unaffordable, as it is a time, money, and human resource consuming process, involving very technical complications such as "data conversion, cartographic design, and system design" [96]. Hence, WGPHSS development occurs 
in developed countries much more often than in developing ones. Findings from our review show that development costs can be reduced in the following three ways.

\subsubsection{Collaboration}

Collaborating within public health sectors, whether locally, regionally, nationally, or internationally, can reduce development costs. Besides enabling monitoring health phenomena at different spatial scales, this approach can also benefit the development and management of integrated systems by reducing duplicated efforts. The importance of collaboration was emphasized in previous research [4,7] and recent studies have illustrated the adoption of this collaboration paradigm in WGPHSS development. For instance, the CDC developed Rapid Data Collector, a Web-based system for sharing health information with stakeholders while ensuring that other governmental agencies could utilize the system [97]. Likewise, Canada initiated the Canadian Integrated Public Health Surveillance (CIPHS) project [98], attempting to remove barriers to integrating health surveillance data from different levels and systems. In addition to reducing costs, collaboratively developing a WGPHSS by health sectors at various organizational levels has the potential to avoid the inaccuracy and inconsistency issues in data collected at different spatial levels, in different data formats, and from different sources [99]. Another added benefit attributable to health sector collaboration is that PHS is no longer limited to arbitrarily-defined administrative regions. Given that diseases have no political boundaries [17], this makes more sense, especially in the context of conducting surveillance and data analysis. Public health sectors in different countries have collaborated to develop WGPHSSs for cross-border use. For example, Gao et al. [100] and Moreno-Sanchez et al. [17] developed WGPHSSs to monitor diseases across the Canada-USA and USA-Mexico borders, respectively.

Interdisciplinary collaboration is also needed. The sources provided in the identified journal articles and the sheer volume of literature suggested that various disciplines, including (Web) GIS, spatial epidemiology or medical geography, information technology and Web engineering, and public health, have made efforts to develop WGPHSSs since 2000. In practice, it is almost impossible for a person to possess all the required knowledge to coordinate and develop a successful WGPHSS. The academic community can collaborate to help train capable personnel by providing cross-disciplinary courses, thus contributing to the development of WGPHSSs.

\subsubsection{Reuse or Adapt Existing WGPHSSs}

Theoretically, with slight changes, a WGPHSS can be reused or adapted to monitor any kind of health phenomena. Currently, there are a number of successful cases. For example, a host of WGPHSSs (Global Health Atlas, FluNet, and DengueNet; AEGIS and AEGIS Flu; Google Flu Trends and Google Dengue Trends) were developed with the same platform. Another instance is that the Hong Kong government developed an infectious-disease surveillance system by integrating health components into an existing GIS platform. Reusing or adapting existing WGPHSSs can significantly reduce the development costs, which is especially important for low-income countries where costs are prohibitive. This cost-effectiveness also makes monitoring overlooked health phenomena feasible. The WHO defines health as "a state of complete physical, mental and social well-being and not merely the absence of disease or infirmity" [101]. This definition highlights the necessity of monitoring the 
physical, behavioral, and mental health of the population. Our review, however, indicates that most WGPHSSs are concerned with monitoring infectious diseases. Therefore, determining how to reuse or adapt current WGPHSSs for monitoring ignored health phenomena is a pre-dominant issue that requires further research. Moreover, although some WGPHSSs have been reused or adapted for other surveillance purposes, evaluation is still necessary to determine how successfully the WGPHSS has been adapted to its new purpose.

\subsubsection{Adopt Geomashup and Open-Source Models}

Geomashup and open-source models should be further adopted for the WGPHSS development, especially in low-resource areas. A WGPHSS in the form of a geomashup has the potential to weave any distributed spatial and non-spatial resources over the Web, thus enabling developers to save the costs of collecting or preparing data (base maps or thematic health data) and developing analytical functions. We observed that only Google Maps has been used as the base map in explored WGPHSSs; however, we can anticipate other freely available (probably with usage limits) maps, such as Bing Maps and Yahoo! Maps, being used in the near future. The increasing availability of browser-side APIs, such as ArcGIS API for Javascript, Flex, and Silverlight, has provided an easy and lightweight programming model for building geomashups, thus empowering non-technical experts to develop an effective WGPHSS and potentially reducing human resource costs. In contrast to the widespread use of geomashups, the open-source model is underutilized for WGPHSS development with only a few exceptions [17,102], probably because using open-source platform or software demands more advanced programming knowledge compared with building geomashups [103]. However, we believe this development model should be adopted more in the long run, as it maximizes the interoperability, reusability, and extensibility of the WGPHSSs in addition to greatly reducing licensing costs. Additional advantages of using open-source software or platform in health informatics were discussed in previous studies [16,17]. Some projects, such as AEGIS and EpiScanGIS, have released their source code to the public, most likely due to the realization of the significant advantage of utilizing the open-source model. Likewise, BioCaster has made its ontology and software resources (e.g., the rule engine that drives the text mining system) available for public access and feedback [22].

Furthermore, both models can facilitate cooperation and collaborations between different sectors within or between nations at different spatial levels. For instance, information on health conditions and health determinants can be separately prepared by different sectors and provided as different Web services and then be mixed to form a geomashup-style WGPHSS. On the other hand, WGPHSSs developed with the same open-source platform or software can interoperate with each other if collaboratively monitoring cross-border health phenomena is needed.

\subsection{Training}

Parallel with WGPHSS development, end user training is necessary, especially for enabling proper map customization and use of analysis functions in WGPHSSs, as not all WGPHSS users have a GIS, cartography, or statistics background. Lack of funding may impede the provision of classroom training; however, adding training materials into system websites can facilitate training, thereby making Web GIS more cost-effective than desktop GIS [8]. This training method has already been 
implemented in several systems. For instance, the manual for EpiScanGIS has been integrated into its website. Likewise, the CDC supplies an online training module for learning GIS. Other efforts have also been initiated to train end users over the Internet. For example, a Web portal named Geovisual Explication (G-EX) has been developed to help public health professionals learn new geo-visualization tools and spatial analysis methods [104].

In spite of its potential contributions, this review has limitations. One is that it is not exhaustively comprehensive. A few WGPHSSs were inaccessible or could not be found online and therefore could not be included as part of the analysis. For WGPHSSs monitoring infectious diseases, some may have been discarded after the disease outbreaks were brought under control. Moreover, we relied on the Google search engine only to locate WGPHSSs. As such, this may have generated incomplete or biased information. We attempted to mitigate this problem by searching for WGPHSSs from the bibliographic databases as well. Furthermore, we reviewed English-language journal articles and WGPHSSs (or WGPHSSs with English versions) only, therefore may have omitted relevant WGPHSSs in other languages.

\section{Conclusions}

As an interdisciplinary field, WGPHSSs have been developed to keep pace with the advancement of Web technologies and GIS. Nevertheless, GIS functionalities in PHS are still substantially underdeveloped in a Web context in comparison with a desktop context. In particular, WGPHSSs lag behind significantly in terms of providing users with robust methods of spatial analysis [105,106]. Geographical and performance inequalities still largely exist in WGPHSS development. Although WGPHSSs have been widely accepted in developed countries, especially in the U.S., developing countries and low-resource regions have been slow to adopt WGPHSSs primarily due to prohibitive costs and a lack of infrastructure to support the necessary data requirements. Developing a successful WGPHSS requires collaborations of multiple disciplines. Academia can play an important role in advancing WGPHSSs by providing courses that cover knowledge of Web GIS, PHS, spatial statistical analysis in public health, and computing. Technologies in the Web 2.0 era, including mobile devices, neo-geography, news and social media, have the potential for timely collection of geo-referenced health data and offer the possibility of large scale PHS. Integrating health-related data from multiple sources and enhancing the data analysis functions in WGPHSSs to improve their performance are challenges that require concerted efforts. WGPHSSs exclusively for public health practitioners need to be made accessible to other professionals (e.g., urban planners). However, a suitable balance still needs to be struck between PHS and privacy issues. To reduce the resources required for developing effective WGPHSSs, reusing or adapting current WGPHSSs for monitoring other (particularly overlooked) health phenomena, adopting geomashup or open-source models, and strengthening local, regional, national, and global collaborations are essential. While this paper focuses on how WGPHSSs can be successfully developed, further research is needed on how successful these WGPHSSs have been practically applied for health interventions, research, or education. Findings would in turn enhance the success of WGPHSS development. 


\section{Acknowledgments}

This work was supported by the Natural Science and Engineering Research Council of Canada (grant number RGPIN-371625-2009). We would like to acknowledge the anonymous reviewers for their insightful comments and suggestions. We also thank Kang Mengjun from Wuhan University, China, for his great advice on Web GIS, and Andrew Leung and the editors for their input in language editing.

\section{Author Contributions}

Both authors conceived the manuscript. Hui Luan conducted the literature review and drafted the manuscript. Jane Law guided the development of the manuscript and critically revised the manuscript. Both authors have read and approved the final manuscript.

\section{Conflicts of Interest}

The authors declare no conflict of interest.

\section{References}

1. Cinnamon, J.; Rinner, C.; Cusimano, M.D.; Marshall, S.; Bekele, T.; Hernandez, T.; Glazier, R.H.; Chipman, M.L. Online map design for public-health decision makers. Cartographica 2009, 44, 289-300.

2. Cromley, E.K. GIS and disease. Annu. Rev. Public Health 2003, 24, 7-24.

3. Boulos, M.N.K. Towards evidence-based, GIS-driven national spatial health information infrastructure and surveillance services in the United Kingdom. Int. J. Health Geogr. 2004, 3, 1-50.

4. Nykiforuk, C.I.J.; Flaman, L.M. Geographic Information Systems (GIS) for health promotion and public health: A review. Health Promot. Pract. 2011, 12, 63-73.

5. Duncombe, J.; Clements, A.; Hu, W.; Weinstein, P.; Ritchie, S.; Espino, F.E. Review: Geographical information systems for dengue surveillance. Am. J. Trop. Med. Hyg. 2012, 86, 753-755.

6. Edelman, L.S. Using geographic information systems in injury research. J. Nurs. Scholarsh. 2007, 39, 306-311.

7. Croner, C.M. Public health, GIS, and the internet. Annu. Rev. Public Health 2003, 24, 57-82.

8. Maclachlan, J.C.; Jerrett, M.; Abernathy, T.; Sears, M.; Bunch, M.J. Mapping health on the Internet: A new tool for environmental justice and public health research. Health Place 2007, 13, 72-86.

9. Fisher, R.P.; Myers, B.A. Free and simple GIS as appropriate for health mapping in a low resource setting: A case study in Eastern Indonesia. Int. J. Health Geogr. 2011, 10, doi:10.1186/1476-072X-10-15.

10. Kearns, F.R.; Kelly, M.; Tuxen, K.A. Everything happens somewhere: Using WebGIS as a tool for sustainable natural resource management. Front. Ecol. Environ. 2003, 1, 541-548.

11. Nash, D.; Elul, B.; Rabkin, M.; Tun, M.; Saito, S.; Becker, M.; Nuwagaba-biribonwoha, H. Strategies for more effective monitoring and evaluation systems in HIV programmatic scale-up in resource-limited settings: Implications for health systems strengthening. J. Acquir. Immune Defic. Syndr. 2009, 52, 58-62. 
12. Fu, P.; Sun, J. GIS in the Web Era. In Web GIS: Principles and Applications; Fu, P., Sun, J., Eds.; ESRI Press: Redlands, CA, USA, 2011; pp. 1-24.

13. Fu, P.; Zhu, Y.; Sun, J. Hot Topics and New Frontiers. In Web GIS: Principles and Applications; Fu, P., Sun, J., Eds.; ESRI Press: Redlands, CA, USA, 2011; pp. 249-280.

14. Thacker, S.B. Historical Development. In Principles \& Practice of Public Health Surveillance; Lee, L.M., Teutsch, S.M., Thacker, S.B., St. Louis, M.E., Eds.; Oxford University Press: New York, NY, USA, 2010; pp. 1-17.

15. Fu, P.; Sun, J. Geospatial Mashups. In Web GIS: Principles and Applications; Fu, P., Sun, J., Eds.; ESRI Press: Redlands, CA, USA, 2011; pp. 89-114.

16. Anderson, G.; Moreno-Sanchez, R. Building web-based spatial information solutions around open specifications and open source software. Trans. GIS 2003, 7, 447-466.

17. Moreno-Sanchez, R.; Anderson, G.; Cruz, J.; Hayden, M. The potential for the use of Open Source Software and Open Specifications in creating We-based cross-border health spatial information systems. Int. J. Geogr. Inf. Sci. 2007, 21, 1135-1163.

18. Rinner, C.; Moldofsky, B.; Cusimano, M.D.; Marshall, S.; Hernandez, T. Exploring the boundaries of web map services: The example of the online injury atlas for Ontario. Trans. GIS 2011, 15, 129-145.

19. Kistemann, T.; Dangendorf, F.; Schweikart, J. New perspectives on the use of Geographical Information Systems (GIS) in environmental health sciences. Int. J. Hyg. Environ. Health 2002, 205, 169-181.

20. Michael, P. Maps and the Internet: An Introduction. In Maps and the Internet; Elsevier Science Ltd.: Oxford, UK, 2003; pp. 1-16.

21. AEGIS Flu. Available online: http://aegis.chip.org/flu (accessed on 6 August 2013).

22. BioCaster. Available online: http://born.nii.ac.jp (accessed on 6 August 2013).

23. CDC: Behavioral Risk Factor Surveillance System. Available online: http://www.cdc.gov/brfss (accessed on 6 August 2013).

24. CDC: Diabetes Public Health Resource. Available online: http://www.cdc.gov/diabetes (accessed on 6 August 2013).

25. CDC: Division for Heart Disease and Stroke Prevention. Available online: http://www.cdc.gov/dhdsp (accessed on 6 August 2013).

26. CDC: Division of Oral Health. Available online: http://www.cdc.gov/OralHealth (accessed on 6 August 2013).

27. CDC: U.S. Cancer Statistics: An Interactive Atlas. Available online: http://apps.nccd.cdc.gov/ DCPC_INCA (accessed on 6 August 2013).

28. CDC: WISQARSTM. Available online: http://www.cdc.gov/injury/wisqars (accessed on 6 August 2013).

29. CDC: WNV Activity \& Surveillance. Available online: http://www.cdc.gov/westnile (accessed on 6 August 2013).

30. Community Health Information System: Breast Health Portal. Available online: http://interactive-mapping.slehc.org/breast-health-portal/census.aspx (accessed on 6 August 2013).

31. Community Health Information System: Project Safety Net. Available online: http://interactive-mapping.slehc.org/project-safety-net/zip.aspx (accessed on 6 August 2013). 
32. EpiScanGIS. Available online: http://www.episcangis.org (accessed on 6 August 2013).

33. EpiSPIDER. Available online: http://www.epispider.org (accessed on 6 August 2013).

34. FloridaCHARTS. Available online: http://www.floridacharts.com (accessed on 6 August 2013).

35. FluBreaks. Available online: http://dritte.org/flubreaks (accessed on 6 August 2013).

36. Google Dengue Trends. Available online: http://www.google.org/denguetrends (accessed on 6 August 2013).

37. Google Flu Trends. Available online: http://www.google.org/flutrends (accessed on 6 August 2013).

38. HealthMap. Available online: http://www.healthmap.org (accessed on 6 August 2013).

39. Kentucky Cancer Registry. Available online: http://www.cancer-rates.info/ky (accessed on 6 August 2013).

40. Malaria Atlas Project. Available online: http://www.map.ox.ac.uk (accessed on 6 August 2013).

41. Pennsylvania's West Nile Virus Surveillance Program. Available online: http://www. westnile.state.pa.us (accessed on 6 August 2013).

42. Public Health Agency of Canada: West Nile Virus Monitor. Available online: http://www.phac-aspc.gc.ca/wnv-vwn/index-eng.php (accessed on 6 August 2013).

43. Sentinelles. Available online: http://www.sentiweb.org (accessed on 6 August 2013).

44. Smittskyddsinstitutet. Available online: http://www.smittskyddsinstitutet.se (accessed on 6 August 2013).

45. WHO: DengueNet. Available online: http://www.who.int/denguenet (accessed on 6 August 2013).

46. WHO: FluNet. Available online: http://www.who.int/influenza/gisrs_laboratory/flunet (accessed on 6 August 2013).

47. WHO: Global Health Atlas. Available online: http://apps.who.int/globalatlas (accessed on 6 August 2013).

48. What is EpiScanGIS? Available online: http://www.episcangis.org/whatis.vm (accessed on 4 January 2014).

49. Reinhardt, M.; Elias, J.; Albert, J.; Frosch, M.; Harmsen, D.; Vogel, U. EpiScanGIS: An online geographic surveillance system for meningococcal disease. Int. J. Health Geogr. 2008, 7, doi:10.1186/1476-072X-7-33.

50. Heaivilin, N.; Gerbert, B.; Page, J.E.; Gibbs, J.L. Public health surveillance of dental pain via Twitter. J. Dent. Res. 2011, 90, 1047-1051.

51. Signorini, A.; Segre, A.M.; Polgreen, P.M. The use of twitter to track levels of disease activity and public concern in the U.S. during the Influenza A H1N1 pandemic. PLoS One 2011, 6, doi:10.1371/journal.pone.0019467.

52. Chunara, R.; Andrews, J.R.; Brownstein, J.S. Social and news media enable estimation of epidemiological patterns early in the 2010 Haitian Cholera Outbreak. Am. J. Trop. Med. Hyg. 2012, 86, 39-45.

53. Diaz-Aviles, E.; Stewart, A. Tracking Twitter for Epidemic Intelligence. Case study: EHEC/HUS Outbreak in Germany, 2011. In Proceedings of the 3rd Annual ACM Web Science Conference, WebSci 2012, New York, NY, USA, 22-24 June 2012; pp. 82-85.

54. Hulth, A.; Rydevik, G. Web Query-Based Surveillance in Sweden During the Influenza A(H1N1) 2009 Pandemic, April 2009 to February 2010. Available online: http://www.eurosurveillance.org/ViewArticle.aspx?ArticleId=19856 (accessed on 6 August 2013). 
55. Yin, S.; Ho, M. Monitoring a toxicological outbreak using internet search query data. Clin. Toxicol. (Phila.) 2012, 50, 818-822.

56. Malik, M.T.; Gumel, A.; Thompson, L.H.; Strome, T.; Mahmud, S.M. "Google Flu Trends" and emergency department triage data predicted the 2009 pandemic H1N1 waves in Manitoba. Can. J. Public Health 2011, 102, 294-297.

57. Ortiz, J.R.; Zhou, H.; Shay, D.K.; Neuzil, K.M.; Fowlkes, A.L.; Goss, C.H. Monitoring influenza activity in the United States: A comparison of traditional surveillance systems with Google Flu Trends. PLoS One 2011, 6, doi:10.1371/journal.pone.0018687.

58. Valdivia, A.; Lopez-Alcalde, J.; Vicente, M.; Pichiule, M.; Ruiz, M.; Ordobas, M. Monitoring Influenza Activity in Europe with Google Flu Trends: Comparison with the Findings of Sentinel Physician Networks-Results for 2009-10. Available online: http://www.eurosurveillance.org/ ViewArticle.aspx?ArticleId=19621 (accessed on 6 August 2013).

59. Wada, K.; Ohta, H.; Aizawa, Y. Correlation of "Google Flu Trends" with sentinel surveillance data for influenza in 2009 in Japan. Open Public Health J. 2011, 4, 17-20.

60. Kang, M.; Zhong, H.; He, J.; Rutherford, S.; Yang, F. Using Google Trends for influenza surveillance in South China. PLoS One 2013, doi:10.1371/journal.pone.0055205.

61. Wilson, N.; Mason, K.; Tobias, M.; Peacey, M.; Huang, Q.; Baker, M. Interpreting “Google Flu Trends" Data for Pandemic H1N1 Influenza: The New Zealand Experience. Available online: http://www.eurosurveillance.org/ViewArticle.aspx?ArticleId=19386 (accessed on 6 August 2013).

62. Carneiro, H.A.; Mylonakis, E. Google trends: A web-based tool for real-time surveillance of disease outbreaks. Clin. Infect. Dis. 2009, 49, 1557-1564.

63. Goranson, C.; Thihalolipavan, S.; de Tada, N. VGI and Public Health: Possibilities and Pitfalls. In Crowdsourcing Geographic Knowledge: Volunteered Geographic Information (VGI) in Theory and Practice; Sui, D.Z., Elwood, S., Goodchild, M.F., Eds.; Springer: Dordrecht, NY, USA, 2013; pp. 329-340.

64. Boulos, M.N.K.; Wheeler, S.; Tavares, C.; Jones, R. How smartphones are changing the face of mobile and participatory healthcare: An overview, with example from eCAALYX. Biomed. Eng. Online 2011, 10, doi:10.1186/1475-925X-10-24.

65. Weitzman, E.R.; Adida, B.; Kelemen, S.; Mandl, K.D. Sharing data for public health research by members of an international online diabetes social network. PLoS One 2011, 6, doi:10.1371/journal.pone.0019256.

66. Boulos, M.N.K.; Resch, B.; Crowley, D.N.; Breslin, J.G.; Sohn, G.; Burtner, R. Crowdsourcing, citizen sensing and sensor web technologies for public and environmental health surveillance and crisis management: Trends, OGC standards and application examples. Int. J. Health Geogr. 2011, 10, doi:10.1186/1476-072X-10-67.

67. Olson, J.A. Health-related geospatial data and social media: Can you harvest geosocial data? J. Map Geogr. Libr. 2011, 7, 377-381.

68. SwiftRiver. Available online: http://www.ushahidi.com/products/swiftriver-platform (accessed on 19 December 2013).

69. St Louis, C.; Zorlu, G. Can Twitter predict disease outbreaks? BMJ 2012, 344, doi:10.1136/bmj.e2353. 
70. DIZIE: Disease Information Extraction from Tweets. Available online: http://born.nii.ac.jp/dizie (accessed on 6 August 2013).

71. Scotch, M.; Yip, K.Y.; Cheung, K.-H. Development of grid-like applications for public health using Web 2.0 mashup techniques. J. Am. Med. Inform. Assoc. 2008, 15, 783-786.

72. Collier, N.; Doan, S.; Kawazoe, A.; Goodwin, R.M.; Conway, M.; Tateno, Y.; Ngo, Q.; Dien, D.; Kawtrakul, A.; Takeuchi, K.; et al. BioCaster: Detecting public health rumors with a web-based text mining system. Bioinformatics 2008, 24, 2940-2941.

73. Keller, M.; Freifeld, C.C.; Brownstein, J.S. Automated vocabulary discovery for geo-parsing online epidemic intelligence. BMC Bioinform. 2009, 9, 1-9.

74. Cinnamon, J.; Schuurman, N. Injury surveillance in low-resource settings using geospatial and social web technologies. Int. J. Health Geogr. 2010, 9, doi:10.1186/1476-072X-9-25.

75. Glynn, M.K.; Backer, L.C. Collecting Public Health Surveillance Data. In Principles \& Practice of Public Health Surveillance; Lee, L.M., Teutsch, S.M., Thacker, S.B., St. Louis, M.E., Eds.; Oxford University Press: New York, NY, USA, 2010; pp. 44-64.

76. Velikic, G.; Sukic, E.; Jevtovic-Stoimenov, T.; Bocko, M.F.; Stoimenov, L.; Pentland, A. Ongoing diagnostics mapped: From an individual to the community health index. HealthMED 2012, 6, 3152-3157.

77. Koenig, A.; Samarasundera, E.; Cheng, T. Interactive map communication: Pilot study of the visual perceptions and preferences of public health practitioners. Public Health 2011, 125, 554-560.

78. McKee, K.T., Jr; Shields, T.M.; Jenkins, P.R.; Zenilman, J.M.; Glass, G.E. Application of a geographic information system to the tracking and control of an outbreak of shigellosis. Clin. Infect. Dis. 2000, 31, 728-733.

79. Best, N.; Richardson, S.; Thomson, A. A comparison of Bayesian spatial models for disease mapping. Stat. Methods Med. Res. 2005, 14, 35-59.

80. Highfield, L.; Arthasarnprasit, J.; Ottenweller, C.A.; Dasprez, A. Interactive web-based mapping: Bridging technology and data for health. Int. J. Health Geogr. 2011, 10, doi:10.1186/1476-072X-10-69.

81. Bernier, E.; Gosselin, P.; Badard, T.; Bédard, Y. Easier surveillance of climate-related health vulnerabilities through a Web-based spatial OLAP application. Int. J. Health Geogr. 2009, 8, doi:10.1186/1476-072X-8-18.

82. Frank, A.U. The Use of Geographical Information System: The User Interface is the System. In Human Factors in Geographical Information Systems; Medyckyj-Scott, D., Hearnshaw, H.M., Eds.; Belhaven Press: London, UK, 1993; pp. 3-14.

83. Theseira, M. Using internet GIS technology for sharing health and health related data for the West Midlands Region. Health Place 2002, 8, 37-46.

84. Bell, B.S.; Hoskins, R.E.; Pickle, L.W.; Wartenberg, D. Current practices in spatial analysis of cancer data: Mapping health statistics to inform policymakers and the public. Int. J. Health Geogr. 2006, 5, doi:10.1186/1476-072X-5-49.

85. Griffin, A.L.; Maceachren, A.M.; Hardisty, F.; Steiner, E.; Li, B. A comparison of animated maps with static small-multiple maps for visually identifying space-time clusters. Ann. Assoc. Am. Geogr. 2006, 96, 740-753.

86. Harrower, M. A look at the history and future of animated maps. Cartographica 2004, 39, 33-42. 
87. Cinnamon, J.; Rinner, C.; Cusimano, M.D.; Marshall, S.; Bakele, T.; Hernandez, T.; Glazier, R.H.; Chipman, M.L. Evaluating web-based static, animated and interactive maps for injury prevention. Geospat. Health 2009, 4, 3-16.

88. Beyer, K.M.M.; Rushton, G. Mapping Cancer for Community Engagement. Available online: http://www.cdc.gov/pcd/issues/2009/jan/08_0029.htm (accessed on 6 August 2013).

89. Obesity in the U.S., 2008. Available online: http://hci.stanford.edu/jheer/files/zoo (accessed on 4 August 2013).

90. Isopleth Map of H1N1 Deaths in California (November 10, 2009). Available online: http://www.flutrackers.com/forum/showthread.php?t=132504 (accessed on 19 May 2013).

91. AIDS Incidence 2004. Available online: http://www.cdc.gov/gis/mg_aids_incidence_2004.htm (accessed on 19 May 2013).

92. Pennsylvania Cancer Atlas. Available online: http://www.geovista.psu.edu/grants/CDC (accessed on 20 April 2013).

93. Fu, P.; Yin, F.; Sun, J. Technical Basics. In Web GIS: Principles and Applications; Fu, P., Sun, J., Eds.; ESRI Press: Redlands, CA, USA, 2011; pp. 25-48.

94. Brownstein, J.S.; Cassa, C.; Isaac, S.; Mandl, K.D. Reverse Geocoding: Concerns about Patient Confidentiality in the Display of Geospatial Health Data. AMIA Annu. Symp. Proc. 2005, v.2005, 905. Available online: http:/www.ncbi.nlm.nih.gov/pmc/articles/PMC1560748/ (accessed on 1 May 2013).

95. AbdelMalik, P.; Boulos, M.N.K.; Jones, R. The perceived impact of location privacy: A web-based survey of public health perspectives and requirements in the UK and Canada. BMC Public Health 2008, 8, doi:10.1186/1471-2458-8-156.

96. Tsoi, C. Development of a Cross-Domain Web-Based GIS Platform to Support Surveillance and Control of Communicable Diseases. In Proceedings of the International Conference in GIS and Health, Hong Kong, China, 27-29 June, 2006; pp. 44-56.

97. Morton, M.; Levy, J.L. Challenges in disaster data collection during recent disasters. Prehosp. Disaster Med. 2011, 26, 196-201.

98. Canadian Integrated Public Health Surveillance (CIPHS). Available online: http://www.phac-aspc.gc.ca/php-psp/ciphs-eng.php (accessed on 25 June 2012).

99. Li, L.; Xu, L.; Jeng, H.A.; Naik, D.; Allen, T.; Frontini, M. Creation of environmental health information system for public health service: A pilot study. Inf. Syst. Front. 2008, 10, 531-542.

100. Gao, S.; Mioc, D.; Anton, F.; Yi, X.; Coleman, D.J. Online GIS services for mapping and sharing disease information. Int. J. Health Geogr. 2008, 7, doi:10.1186/1476-072X-7-8.

101. WHO definition of Health. Available online: http://www.who.int/about/definition/en/print.html (accessed on 12 May 2013).

102. Vanmeulebrouk, B.; Rivett, U.; Ricketts, A.; Loudon, M. Open source GIS for HIV AIDS management. Int. J. Health Geogr. 2008, 7, doi:10.1186/1476-072X-7-53.

103. Hall, G.B.; Chipeniuk, R.; Feick, R.D.; Leahy, M.G.; Deparday, V. Community-based production of geographic information using open source software and Web 2.0. Int. J. Geogr. Inf. Sci. 2010, 24, 761-781.

104. Robinson, A.C.; MacEachren, A.M.; Roth, R.E. Designing a web-based learning portal for geographic visualization and analysis in public health. Health Inform. J. 2011, 17, 191-208. 
105. Law, J.; Haining, R.; Maheswaran, R.; Pearson, T. Analyzing the relationship between smoking and coronary heart disease at the small area level: A Bayesian approach to spatial modeling. Geogr. Anal. 2006, 38, 140-159.

106. Haining, R.; Law, J.; Griffith, D. Modelling small area counts in the presence of overdispersion and spatial autocorrelation. Comput. Stat. Data Anal. 2009, 53, 2923-2937.

\section{Appendix}

A list of identified but excluded systems as well as their websites is shown in Table A1. These systems were divided into four groups based on the reasons why they were excluded.

Table A1. List of excluded systems.

\begin{tabular}{|c|c|}
\hline Name & Website \\
\hline \multicolumn{2}{|c|}{ 1. Not continuously update health data } \\
\hline Cancer Mortality Maps & http://ratecalc.cancer.gov [A1] \\
\hline EpiVue & https://epivue.cphi.washington.edu [A2] \\
\hline Pennsylvania Cancer Atlas & http://www.geovista.psu.edu/grants/CDC [92] \\
\hline \multicolumn{2}{|l|}{ 2. Not entirely about public health } \\
\hline DATA.GOV & http://www.data.gov [A3] \\
\hline \multicolumn{2}{|l|}{ HRSA: Health Resources and } \\
\hline Services Administration Data & http://datawarehouse.hrsa.gov [A4] \\
\hline \multicolumn{2}{|l|}{ Warehouse } \\
\hline U.S. Geological Survey & http://www.usgs.gov [A5] \\
\hline \multicolumn{2}{|c|}{ 3. Exclusively accessible to professionals } \\
\hline AEGIS & http://aegis.chip.org [A6] \\
\hline Online Injury Atlas for Ontario & $\begin{array}{l}\text { http://arrowsmith.geog.utoronto.ca/GeoConnections [A7] } \\
\text { (Note: maps are restricted to professionals) }\end{array}$ \\
\hline \multicolumn{2}{|l|}{ 4. Not physically running online } \\
\hline \multicolumn{2}{|c|}{ Environmental Health Information System (EHIS) [99] } \\
\hline \multicolumn{2}{|l|}{ Epinome [A8] } \\
\hline \multicolumn{2}{|l|}{ GODS $^{\mathrm{N}}[\mathrm{A} 9]$} \\
\hline \multicolumn{2}{|c|}{ Infectious disease surveillance system based on HKSAR Geospatial Information Hub [96] } \\
\hline \multicolumn{2}{|c|}{ Integrated System for Public Health Monitoring of West Nile Virus (ISPHM-WNV) [A10] } \\
\hline \multicolumn{2}{|c|}{ Mapping Infectious Disease Across the New Brunswick-Maine border [100] } \\
\hline \multicolumn{2}{|c|}{ Public Health Agency of Canada_-Disease Surveillance On-Line [8] } \\
\hline \multicolumn{2}{|l|}{ Web Epi [A11] } \\
\hline Web-Based Integrated Birth Def & Surveillance System in New York State [A12] \\
\hline
\end{tabular}

\section{Appendix Reference}

A1. Cancer Mortality Maps. Available online: http://ratecalc.cancer.gov (accessed on 6 August 2013).

A2. EpiVue. Available online: https://epivue.cphi.washington.edu (accessed on 6 August 2013).

A3. Oakes, J.M.; Mâsse, L.C.; Messer, L.C. Work Group III: Methodologic issues in research on the food and physical activity environments: Addressing data complexity. Am. J. Prev. Med. 2009, 36, S177-S181. 
A4. HRSA: Health Resources and Services Administration Data Warehouse. Available online: http://datawarehouse.hrsa.gov (accessed on 6 August 2013).

A5. U.S. Geological Survey. Available online: http://www.usgs.gov (accessed on 6 August 2013).

A6. AEGIS. Available online: http://aegis.chip.org (accessed on 6 August 2013).

A7. Online Injury Atlas for Ontario. Available online: http://arrowsmith.geog.utoronto.ca/ GeoConnections (accessed on 6 August 2013).

A8. Livnat, Y.; Rhyne, T.-M.; Samore, M.H. Epinome: A visual-analytics workbench for epidemiology data. IEEE Comput. Graph. Appl. 2012, 32, 89-95.

A9. Khan, S.A.; Patel, C.O.; Kukafka, R. GODS ${ }^{\mathrm{N}}$ : Global news driven disease outbreak and surveillance. AMIA Annu. Symp. Proc. 2006, v.2006, 983. Available online: http://www.ncbi.nlm.nih.gov/pmc/articles/PMC1839736/ (accessed on 1 May 2013).

A10. Gosselin, P.; Lebel, G.; Rivest, S.; Douville-Fradet, M. The Integrated System for Public Health Monitoring of West Nile Virus (ISPHM-WNV): A real-time GIS for surveillance and decision-making. Int. J. Health Geogr. 2005, 4, doi:10.1186/1476-072X-4-21.

A11. Shi, H.; Zhang, Y.; Zhang, J.; Wan, P.; Shaw, K. Development of Web-Based Epidemiological Reporting System for Tasmania Utilizing a Google Maps Add-on. In Proceedings of the Digital Image Computing Techniques and Applications: 9th Biennial Conference of Australian Pattern Recognition Society, DICTA, Glenelg, SA, Australia, 2007; pp. 118-123.

A12. Wang, Y.; Tao, Z.; Cross, P.K.; Le, L.H.; Steen, P.M.; Babcock, G.D.; Druschel, C.M.; Hwang, S. Development of a web-based integrated birth defects surveillance system in New York State. J. Public Health Manag. Pract. 2008, 14, 1-10.

(C) 2014 by the authors; licensee MDPI, Basel, Switzerland. This article is an open access article distributed under the terms and conditions of the Creative Commons Attribution license (http://creativecommons.org/licenses/by/3.0/). 